\title{
Auditory interhemispheric transfer in relation to patterns of partial agenesis and hypoplasia of the corpus callosum in spina bifida meningomyelocele
}

\author{
H. JULIA HANNAY, ${ }^{1}$ AMY WALKER, ${ }^{1}$ MAUREEN DENNIS, ${ }^{2}$ LARRY KRAMER, ${ }^{3}$ \\ SUSAN BLASER, ${ }^{4}$ AND JACK M. FLETCHER ${ }^{1}$ \\ ${ }^{1}$ Department of Psychology, University of Houston, Houston, Texas \\ ${ }^{2}$ Program in Neurosciences and Mental Health, Hospital for Sick Children, Toronto, Ontario, Canada \\ ${ }^{3}$ Department of Radiology, University of Texas Health Science Center at Houston, Houston, Texas \\ ${ }^{4}$ Department of Radiology, Hospital for Sick Children, Toronto, Ontario, Canada \\ (Received September 6, 2006; Final Revision April 24, 2008; Accepted April 24, 2008)
}

\begin{abstract}
Spina bifida meningomyelocele with hydrocephalus (SBM) is commonly associated with anomalies of the corpus callosum (CC). We describe MRI patterns of regional CC agenesis and relate CC anomalies to functional laterality based on a dichotic listening test in 90 children with SBM and 27 typically developing controls. Many children with $\operatorname{SBM}(n=40)$ showed regional CC anomalies in the form of agenesis of the rostrum and/or splenium, and a smaller number $(n=20)$ showed hypoplasia (thinning) of all CC regions (rostrum, genu, body, and splenium). The expected right ear advantage (REA) was exhibited by normal controls and children with SBM having a normal or hypoplastic splenium. It was not shown by children with SBM who were left handed, missing a splenium, or had a higher level spinal cord lesion. Perhaps the right hemisphere of these children is more involved in processing some aspects of linguistic stimuli. (JINS, 2008, 14, 771-781.)
\end{abstract}

Keywords: Dichotic listening, Handedness, Neural tube defect, Spinal cord, MRI, Anterior commissure

\section{INTRODUCTION}

Abnormalities of the corpus callosum (CC) in children with congenital brain malformations have been of interest for many years because of the central role of the $\mathrm{CC}$ in interhemispheric transfer (Lassonde \& Jeeves, 1994). Congenital and acquired anomalies of the $\mathrm{CC}$ in humans lead to compromised interhemispheric transfer (IHT) with significant consequences for functional laterality and speed of information relay between the hemispheres (Bryden, 1988a,b; Gazzaniga, 2000). Information about IHT has come from three sources: adult split brain literature, congenital $\mathrm{CC}$ absence literature, and normal children and adults.

The adult split brain individual has been used as a paradigm of disturbed IHT. The split brain literature does not provide an appropriate model for making predictions about

Correspondence and reprint requests to: H. Julia Hannay, Department of Psychology, Heyne Building, University of Houston, 4800 Calhoun, Houston, TX 77204-5052. E-mail: jhannay@uh.edu dichotic listening (DL) performance because difficulties in callosal transfer associated with this disorder primarily result from sudden damage to an already developed CC and produces extreme effects such as complete extinction of identification of stimuli presented to one of the ears in a DL task (Clarke et al., 1993; Musiek et al., 1979). Left ear extinction is also apparent on verbal DL tasks in adults with discrete lesions in the posterior body from surgical removal of a tumor, hemorrhage, aneurysm, lacunar infarcts, or traumatic brain injury (Alexander \& Warren, 1988; Jun \& Nutik, 1985; Pollmann et al., 2002; Sugishita et al., 1995). The latter two studies implicate the splenium as well as the posterior body in auditory IHT. Congenital absence of the $\mathrm{CC}$ from a variety of etiologies has produced mixed findings (Chiarello, 1980; Lassonde et al., 1990). Extreme effects such as extinction have not been reported with complete agenesis of the CC (e.g., Chiarello, 1980; Lassonde et al., 1990).

In individuals with normal neurological functioning, functional laterality and IHT vary depending on age, gender, handedness, and perhaps, individual differences in CC connectivity 
(Westerhausen et al., 2006). There is also evidence that compromise of the CC leads to reorganization of lateralized functions, reflecting its role in enabling functional laterality (Gazzaniga, 2000). However, many individuals with impairment of the CC show preservation of IHT. A disorder of particular interest for understanding the impact of CC anomalies in IHT is spina bifida meningomyelocele with hydrocephalus (SBM) because the disorder is not rare and the affected children have a variety of patterns of partial agenesis and hypoplasia (thinning) of the CC. The purpose of this study is to describe the patterns of $\mathrm{CC}$ dysmorphology in children with SBM and to relate individual differences in CC dysmorphology to IHT.

\section{Spina Bifida Meningomyelocele}

A neural tube defect that is the product of a complex pattern of gene-environment interactions, SBM is associated with distinctive physical, neural, and cognitive manifestations (Fletcher et al., 2005). It is a common, severely disabling birth defect, with current prevalence levels in North America of $0.3-0.5$ per 1000 births (postdietary fortification data; Williams et al., 2005). Children with SBM sustain a disruption of neuroembryogenesis that initiates a cascade of brain events that includes primary central nervous system malformations, secondary hydrocephalus, and changes in brain microstructure (Detrait et al., 2005).

$\mathrm{CC}$ anomalies are part of the prolonged disruption of neuroembryogenesis that characterizes SBM. In a large sample of children with SBM, only $4 \%$ had a normal CC; $52 \%$ had partial agenesis, and $44 \%$ had hypoplasia (Fletcher et al., 2005). Figure 1 shows three patterns of the CC with SBM. The regions of the CC that do or do not develop give evidence of the nature and timing of the insult during gestation, and to some degree, the type of insult (Barkovich, 2005). The CC develops from 7 to 20 weeks after gestation. The genu, the body and then the splenium develop before the rostrum. Within this time period, the sequence of CC development is suggested by the pattern of partial agenesis. If the genu and body are present while the splenium and rostrum are absent, partial agenesis from a congenital disorder are inferred; however, if the rostrum and splenium are present while the genu and body are hypoplastic or absent, a destructive lesion due to secondary hydrocephalus is more likely (Barkovich, 2005).

\section{Auditory IHT and the Dichotic Listening (DL) Paradigm}

Auditory IHT has been well studied in children and adults with the DL paradigm (Kimura, 1961a,b, 1963). Recent fMRI research (Rimol et al., 2006) has confirmed the association of DL asymmetry with left hemisphere language dominance, although this may be task, methodology, and population dependent (Bethmann et al., 2007). DL involves simultaneous presentation of sounds to both ears on each
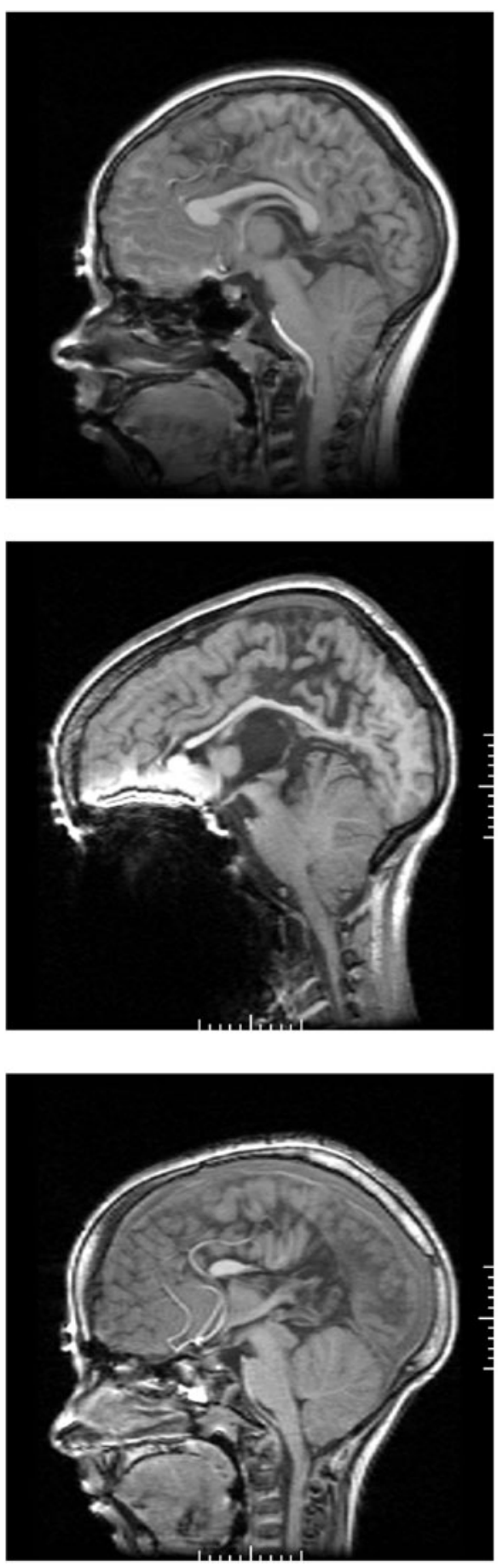

Fig. 1. Midsagittal MRI showing the corpus callosum (CC) of children with spina bifida meningomyelocele (SBM) showing minimal hypoplasia (upper), extensive hypoplasia (middle), and agenesis (absence) of splenium, body, and rostrum (lower).

trial of the task, with the listener reporting what was heard (Bryden, 1982; Hiscock \& Decter, 1988). Left hemisphere language-dominant individuals generally report more digits or consonant-vowel (CV) syllables presented to the right rather than the left ear (a right ear advantage or REA; Bryden, 1982; Kimura, 1963; Springer, 1986), presumably 
reflecting the dominance of direct contralateral pathways to the left hemisphere. CV syllables have proved to be useful in DL studies with adults (Gadea et al., 2000; Hugdahl et al., 2001; McKeever et al., 1984) and children (Caplan \& Kinsbourne, 1981; Geffner \& Dorman, 1976).

\section{DL and Handedness, Age, and Sex}

The REA varies with handedness, age, and sex (Bryden, 1988a). In many studies, left-handers show a smaller or less frequent REA (Cowell \& Hugdahl, 2000; McKeever et al., 1984). Some studies have reported no change or a reduction in the REA for linguistic stimuli with increasing age (Berlin et al., 1973; Kimura, 1963; Knox \& Kimura, 1970; Neijenhuis et al., 2002), while others have reported an increased REA with age (Bryden \& Allard, 1973; Harper \& Kraft, 1994; Satz et al., 1975) that, in some cases, tapers off by adolescence. The relation of sex to DL is equivocal, but any reported differences suggest more lateral asymmetry in males (Hiscock et al., 1994; McGlone, 1980).

\section{Auditory IHT and CC Agenesis}

Auditory IHT tasks have produced variable results in studies of CC agenesis (Hannay, 2000). Using DL, right, left, and no ear advantages have been reported for children with complete $\mathrm{CC}$ agenesis, the REA being most frequent (Bryden \& Zurif, 1970; Chiarello, 1980; Lassonde et al., 1990). A higher rate of left ear advantage (LEA) was found in a small study of children with partial CC agenesis from SBM or aqueduct stenosis on a fused word dichotic listening task (Halwes, 1991) in which only one word is heard (Klaas et al., 1999).

\section{Issues in Studies of Children with Congenital Disorders Involving the Corpus Callosum}

Hannay (2000) reviewed IHT studies involving individuals with either SBM or congenital CC agenesis and discussed their limitations: case studies or relatively small sample size that limits their assessment of the relationship between IHT, dysmorphologies of parts of the CC, other structures, and possible structural markers of severity of SBM, such as level of spinal lesion. Small sample size also limits the evaluation of demographic variables such as age, handedness, and sex. Some studies include individuals having CC agenesis from a variety of disorders and/or individuals with complete agenesis and partial agenesis in the same analyses without considering possible differences in the effects of etiology and type of agenesis. MRI to verify the status of the CC (and structures that might serve as compensatory mechanisms) was rarely used in early studies.

\section{Present Study}

We investigated IHT with a CV syllable DL task in relation to MRI findings for children with SBM and typically devel- oping normal control (NC) children. SBM is a good population in which to study IHT because: (a) CC anomalies are common but not universal, so individual differences in CC status may be studied; (b) CC anomalies manifest in different patterns, including partial dysgenesis of various types and hypoplasia; and (c) mental retardation is not typically present, so that the effects of CC anomalies on IHT may be explored independent of mental retardation.

Our specific hypotheses were:

1. Unlike the NC group, children with SBM will show atypical regional patterns of CC development, including splenium and rostrum agenesis and hypoplasia. Based on information and the fact that the rostrum and splenium are the last regions of the $\mathrm{CC}$ to develop and thus most vulnerable to the effects of SBM, we surmised that the most frequent pattern of $\mathrm{CC}$ agenesis would involve both the rostrum and the splenium (Barkovich, 2005). Complete agenesis was not expected.

2. Right handed NC children will show the typical REA for CV trigrams (Caplan \& Kinsbourne, 1981; Geffner \& Dorman, 1976). Children with SBM will exhibit variable ear effects depending on handedness, the status of the splenium and possibly the body as well as spinal lesion level.

a. A reduced REA or a LEA will occur in children with SBM and non-right handedness. Even without the presence of SBM or callosal anomalies, left-handers often show a reduced REA or even a LEA on dichotic CV tasks (Cowell \& Hugdahl, 2000; McKeever et al., 1984).

b. Right handed children with SBM completely missing the splenium of the CC (and/or perhaps the body) will show an exaggerated REA resulting from reduced identification of CV syllables presented to the left ear indicative of difficulties in callosal transfer but not complete extinction of the perception of left ear stimuli as seen with acquired disorders (Pollmann et al., 2002; Sugishita et al., 1995). Identification of CV syllables to the right ear will be normal because these stimuli would not have to be transferred callosally to be processed.

c. For hypoplasia of the splenium (and/or body), a normal REA will be found for right handed children with SBM, assuming sufficient auditory fibers to support connectivity. If there are two few fibers to support connectivity, the REA will be larger than usual for the same reasons as given in $2 \mathrm{~b}$. No studies of the behavioral effects of hypoplasia have been published to our knowledge.

d. Level of spinal lesion will be related to the severity of dysmorphologies of the brain in SBM, including the status of the splenium of the CC (Fletcher et al., 2005). In SBM, the spinal lesion can occur at any vertebral location on the spine and is determined from pathology reports and medical records. Higher level lesions produce poorer neurobehavioral and brain outcomes, and are also more frequently associated with 
splenial agenesis (Fletcher et al., 2005). We hypothesized that children with higher spinal lesions, but not those with lower spinal lesions, will show an exaggerated REA (for the same reasons as in $2 b$ ).

\section{METHODS}

\section{Participants}

The data for this research were collected in compliance with regulations of the University of Houston, the University of Texas Health Science Center at Houston, and the Hospital for Sick Children in Toronto and their Committees for the Protection of Human Subjects. The final sample comprised 28 typically developing NC children and 90 school-aged children with SBM and shunted hydrocephalus that successfully completed the DL task. Ten children had data, but were dropped for reasons explained below. Children in the NC group were volunteers who responded to local advertising. Participants with SBM were medically stable, recruited from clinics serving children in Houston ( $n=53 \mathrm{SBM} ; 11 \mathrm{NC})$ and The Hospital for Sick Children in Toronto ( $n=37 \mathrm{SBM} ; 17 \mathrm{NC})$. Children in both groups were fluent in English and had either Verbal Reasoning or Visual/Abstract Reasoning scores of at least 70 on the Stanford Binet Test of Intelligence-Fourth Edition (Thorndike et al., 1986). Exclusion criteria were neurological disorders unrelated to SBM, severe psychiatric disorder, uncontrolled seizure disorder, an inability to control the upper limbs, or a serious hearing loss corrected with hearing aids. Hearing was assessed with a Beltone Portable 100 Series Model 109 Audiometer (Beltone Electronics, Glenview, IL). Children with $\geq 20 \mathrm{db}$ difference between the ears and thresholds $\geq$ $60 \mathrm{db}$ in each ear at each frequency for hearing pure tones monaurally at 500, 1000, 2000, and $4000 \mathrm{HZ}$ were excluded $(n=6)$.

Most children with SBM had either 0 or 1 shunt revision ( $n=49$ ), 32 had 2-4 revisions, while 9 had 5-14 revisions. Nineteen had upper level spinal lesions ( $\geq$ T12) and $71 \mathrm{had}$ lower level spinal lesions $(\leq \mathrm{L} 1)$, the differentiation at the thoracic level based on genetic (Volcik et al., 2001) and neuropsychological research (Fletcher et al., 2005).

Table 1 provides group data on age, sex, ethnicity, and socioeconomic status (SES; Hollingshead, 1975) between the NC children and children with SBM. Differences in age, $F(1,116)=2.01 ; p<.16$, and sex, $\chi^{2}<1$, were not significant. A group difference in ethnicity could not be computed because of small samples of Blacks, Asians, and other ethnicities and was not significant for a comparison of Hispanics vs. non-Hispanics, $\chi^{2}(1 ; n=118)=2.18 ; p<$ .14. Consistent with previous reports and the epidemiology of spina bifida (Fletcher et al., 2005), the group with SBM was lower in SES, $F(1,113)=4.12 ; p<.04$. As expected, the group with SBM had lower IQ scores than the NC group, Verbal Reasoning, $F(1,115)=28.91 ; p<.0001$, and Visual Reasoning, $F(1,116)=38.25 ; p<.0001$.
Table 1. Means and standard deviations for sociodemographic and IQ variables by group

\begin{tabular}{lcc}
\hline \hline Variable & NC group & SBM group \\
\hline$n$ & 28 & 90 \\
Age (months) M & 150.1 & 138.9 \\
$S D$ & 40.2 & 35.2 \\
Ethnicity $n$ (\%) & & \\
$\quad$ Caucasian & $22(79 \%)$ & $61(68 \%)$ \\
$\quad$ African American & $2(7 \%)$ & $7(8 \%)$ \\
$\quad$ Hispanic & $2(7 \%)$ & $17(19 \%)$ \\
$\quad$ Asian/Other & $2(7 \%)$ & $5(5 \%)$ \\
Gender & & \\
$\quad$ Female $n$ (\%) & $15(54 \%)$ & $42(47 \%)$ \\
Socioeconomic status* M & 46.0 & 39.7 \\
$\quad S D$ & 12.9 & 14.2 \\
Stanford Binet IQ & & \\
$\quad$ Verbal Reasoning M & 110.6 & 92.8 \\
$\quad S D$ & 11.1 & 16.3 \\
Visual Reasoning M & 111.7 & 91.5 \\
SD & 11.1 & 16.1 \\
\hline \hline
\end{tabular}

*Socioeconomic status was assessed using the methods of Hollingshead (1975).

Handedness, based on drawing preference with a pencil (Beery, 1982), was used as a stand alone measure. As with writing hand, drawing hand has been shown to be a highly reliable, valid item that often occurs in handedness measures used with children, adolescents, and adults (Fennell, 1986; Raczkowski et al., 1974). We used this measure as well as a modified (Fletcher et al., 2005) performance based hand inventory (Satz et al., 1989) that provided a division of children into strong right-, strong left-, and mixed-handers.

\section{PROCEDURES}

\section{MRI Procedures}

All participants underwent MRI imaging sequences on comparable GE Signa 1.5 superconducting magnets (General Electric Medical Systems, Milwaukee, WI) at each site. The three imaging sequences (Fletcher et al., 2005) included an initial sagittal plane spin echo T1-weighted localizer (FOV $24 \mathrm{~cm}$, TR $500 \mathrm{~ms}$, TE $14 \mathrm{~ms}, 256 \times 102$ matrix, $3 \mathrm{~mm}$ with a 0.3 skip, two repetitions). Two whole brain coronal acquisitions were completed: Three-dimensional fast-spin echo T2weighted MR images (FOV $24 \mathrm{~cm}$, TR $4000 \mathrm{~ms}$, TE $102 \mathrm{ms,}$ echo-train length, $256 \times 256$ matrix, one repetition with contiguous $1.7-\mathrm{mm}$ coronal images) and three-dimensional spoiled gradient echo MR images (with contiguous 1.7-mm coronal images (FOV $24 \mathrm{~cm}$, TR $18 \mathrm{~ms}$, TE $3 \mathrm{~ms}$, flip angle $25^{\circ}, 124$ locations, $256 \times 256$ matrix, one repetition). To ensure adequate estimation of CSF versus gray and white matter, separate T1- and T2-weighted acquisitions were necessary. Midsagittal and transaxial slices were examined to visualize the integrity of the corpus callosum. Rostrum, genu, body, 
and splenium were each coded by radiologists in Houston (L.K.) and Toronto (S.B.) as normal, absent, or hypoplastic. The radiologists, who were blinded to patient histories and behavioral data, agreed on conventions and coding criteria based on independent dual coding of MRIs early in the grant. Midsagittal slices for 3 children with SBM appear in Figure 1.

\section{Monotic Listening Task}

A monotic listening task was used to see that the children could hear and discriminate the CV syllables and became familiar with them (Benavidez et al., 1999). The children were told that we wanted to see how well they heard different sounds and the CV syllables were read aloud. The children then underwent 18 trials in which each of $6 \mathrm{CV}$ syllables ( $\mathrm{Ba}, \mathrm{Da}, \mathrm{Ga}, \mathrm{Ka}, \mathrm{Pa}$, and $\mathrm{Ta}$ ) was presented 3 times in a random order to the right ear. A different random order was used for the 18 left ear trials. The number of correct identifications of $\mathrm{CV}$ syllables presented to each ear was determined, with chance being 3 correct responses for each ear.

\section{Task}

The DL task (Benavidez et al., 1999) consisted of 36 pairs of two different $\mathrm{CV}$ syllables used in the monotic task but presented simultaneously. The sequence was repeated in counterbalanced order by reversing the headphones, producing 72 trials. Calibration with a tone of $81 \mathrm{db}$ on the stimulus tape ensured no more than a $0.1 \mathrm{db}$ difference between the output of the left and right earphones at $75 \mathrm{db}$ for the dichotic CV pairs and reduced the chance of enhanced lateral performance from more intense stimulation on one side.

Data from 10/128 children were not used, including two NC children who were inattentive and one who was nonright handed on one of the handedness measures. We wanted a completely right handed NC group for comparison purposes. Data from seven children with SBM were not used for several reasons: frequent prompting to obtain a response $(n=1)$, noncompliance with instruction involving spelling of syllables $(n=1)$, lifting ear phones off ears $(n=1)$, walking off part way through the procedure $(n=3)$, and listening to one ear only based on responses $(n=1)$.

\section{Instructions and Choice of the Dependent Measure}

Children were instructed to listen to two words at the same time, one in each ear, and to report the clearer word first and then the other word, if they could. This reporting strategy has been used successfully in a child with an acquired CC lesion (Benavidez et al., 1999) and typical and atypical adolescents and adults (Gadea et al., 2000; Hugdahl et al., 1995; McKeever et al., 1984; Van Eys and McKeever, 1988).

The mean number of correct $1^{\text {st }}, 2^{\text {nd }}$, and total responses made by the NC and children with SBM were quite similar $(F<1)$ and there was homogeneity of variance across groups for each variable. We used the first (clearest) word reported for our analyses because it is less subject to guessing.

\section{Analytic Techniques}

The dependent measure was the number of correct first responses for $\mathrm{CV}$ stimuli presented to the right and left ears on each trial. Laterality indices were not used because important information concerning the basis for differences in ear effects is lost in these measures (Hellige, 1983; Springer, 1986). For instance, if an REA is larger in one group than another, is it the result of a greater number of correct reports of stimuli presented to the right ear or a lower number of correct reports of stimuli presented to the left ear? Such information can lead to very different interpretations of the findings and difficulties in interpreting IHT in clinical and normal populations.

The NC and SBM data were analyzed separately because most hypotheses involved individual difference variability in CC, handedness, and spinal lesion level within the SBM group that does not exist in the NC group. Data were analyzed with mixed analyses of variance (ANOVAs) in which presentation ear was always the repeated measures factor and a variety of between subjects factors was entered into the model, depending on the analysis. In the analyses of the SBM data, status of the splenium and the body of the CC, level of lesion, handedness, and sex were treated as factors. In the NC group, sex was a factor. Age was as a covariate for both groups.

Both the significance of the effects and the effect sizes are given (Cohen et al., 2003; Tabachnick \& Fidell, 2005). The significance of an effect is determined by many aspects of a study, including sampling and sample size, groups being compared, and measurement of the dependent variable. Effect size gives information about the strength of a relationship in terms of the amount of the variability in the dependent variable that is associated with the independent variables (Cohen et al., 2003) as opposed to merely stating whether a relation exists. Effect sizes were calculated by the SPSS GLM Repeated Measures program as a partial eta $^{2}$ [SSeffect/(SSeffect + SSerror)] (SPSS, 2005). However, the interpretation of the classic eta ${ }^{2}$ as well as partial eta $^{2}$ is still controversial, especially in multi-factor ANOVAS (Cohen, 1973; Levine \& Hullett, 2000; Pierce et al., 2004). The values are reported for consideration by the reader.

An alpha level of .05 was used. Box's Test of equality of the covariance matrices, Mauchley's Test of Sphericity, Box's Test of Equality of Covariance matrices, and Levene's Test of equality of error variances were used to examine underlying assumptions. Pearson's chi square was used to determine the independence of nominal variables.

Chance performance on the DL task was determined as follows: With no ear preference, 36 correct first responses are possible for information presented to the each ear in this 72-trial task. On each trial, one of 6 possible CV syllables could be reported first. If the actual response is random, then chance performance is 6 correct first responses for 
each ear (i.e., 36 possible first responses for each ear divided by the 6 possible syllables).

\section{RESULTS}

\section{MRI Findings}

No children in the normal control group had abnormalities of the CC. The patterns of dysmorphologies of the CC in the children with SBM are given in Table 2. The patterns are given in the posterior to anterior direction of the $\mathrm{CC}$ because our major hypotheses involve the status of the splenium. An examination of the patterns reveals the following facts about status of the splenium and body. The splenium was absent in 29 (32\%), hypoplastic in 49 (54\%), and normal in $12(13 \%)$ of the children with SBM. The body was absent in 2 (2\%), hypoplastic in 77 (86\%), and normal in 11 $(12 \%)$ of the children. The majority of children had a hypoplastic body combined with a hypoplastic splenium $(n=$ 47; 52\%). The next largest group had a hypoplastic body and a missing splenium $(n=27 ; 30 \%)$. Only $2(2 \%)$ were missing both the splenium and the body while none was missing only the body. Relatively few children had a normal body and splenium $(n=9 ; 10 \%)$. The remaining 5 $(5.6 \%)$ had some other combination of body/splenium status. These findings limited the IHT hypotheses tested statistically to the effects of absence/hypoplasia of the splenium and hypoplasia of the body.

Agenesis of the splenium achieved approximately twice as high a frequency in children with upper spinal lesions
$(10 / 19 ; 52.6 \%)$ as in those with lower spinal lesions (19/ $71 ; 26.8 \%)$. Agenesis of the splenium occurred at similar rates in left-handers $(8 / 22 ; 36.4 \%)$ as right-handers $(21 / 68$; $30.9 \%$ ) with SBM. There were too few cases in some cells to cross handedness or upper level lesions with status of the splenium in the analysis of the DL data. These variables were independent of each other (Table 3) as indicated by nonsignificant $\chi^{2}$ for handedness by status of the splenium, $\chi^{2}<1.0$, handedness by lesion level $\left(\chi^{2}<1.0\right)$ and status of the splenium by lesion level $\left(\chi^{2}=4.626 ; p=.099\right)$.

\section{Monotic Listening Task}

Because of ceiling effects on the monotic listening task, we conducted a nonparametric comparison of monotic performance. Mann Whitney U Tests indicated that the monotic level of performance of the NC children and the children with SBM was similar for the right ear CV stimuli $(z=$ 1.172 ) but the NC children correctly identified significantly more left ear CV stimuli $(z=2.28 ; p=.022)$. A median of less than 1 more CV syllable was identified correctly when the syllables were presented to the right ear of NC children $($ Median $=16.0$, range $[($ highest score - lowest score +1$)=$ 6 ] as opposed to children with $\mathrm{SBM}($ Median $=15.5$, range $=$ 10). In the case of CV syllables presented to the left ear monotically, 2 more $\mathrm{CV}$ syllables were identified by the NC children $($ Median $=17.0$, range $=6$ ) than by the children with SBM (Median $=15.0$, range $=12)$. CV syllable identification by the NC and SBM children was well above chance for right and left ears as determined by one sample

Table 2. Regional patterns of the status of the corpus callosum (CC) in children with spina bifida meningomyelocele (SBM) going from posterior to anterior regions

\begin{tabular}{|c|c|c|c|c|c|c|}
\hline & Splenium & Body & Genu & Rostrum & Frequency & Percent \\
\hline 1 & Absent & Absent & Hypoplastic & Absent & 1 & 1.1 \\
\hline 2 & Absent & Absent & Normal & Absent & 1 & 1.1 \\
\hline 3 & Absent & Hypoplastic & Absent & Absent & 2 & 2.2 \\
\hline 4 & Absent & Hypoplastic & Hypoplastic & Absent & 12 & 13.3 \\
\hline 5 & Absent & Hypoplastic & Normal & Absent & 3 & 3.3 \\
\hline 6 & Absent & Hypoplastic & Absent & Normal & 1 & 1.1 \\
\hline 7 & Absent & Hypoplastic & Hypoplastic & Hypoplastic & 3 & 3.3 \\
\hline 8 & Absent & Hypoplastic & Normal & Hypoplastic & 1 & 1.1 \\
\hline 9 & Absent & Hypoplastic & Normal & Normal & 5 & 5.6 \\
\hline 10 & Hypoplastic & Hypoplastic & Normal & Absent & 3 & 3.3 \\
\hline 11 & Hypoplastic & Hypoplastic & Hypoplastic & Absent & 8 & 8.9 \\
\hline 12 & Hypoplastic & Hypoplastic & Hypoplastic & Hypoplastic & 18 & 20.0 \\
\hline 13 & Hypoplastic & Hypoplastic & Normal & Hypoplastic & 7 & 7.8 \\
\hline 14 & Hypoplastic & Hypoplastic & Hypoplastic & Normal & 2 & 2.2 \\
\hline 15 & Hypoplastic & Hypoplastic & Normal & Normal & 9 & 10.0 \\
\hline 16 & Hypoplastic & Normal & Normal & Normal & 1 & 1.1 \\
\hline 17 & Hypoplastic & Normal & Normal & Hypoplastic & 1 & 1.1 \\
\hline 18 & Normal & Hypoplastic & Normal & Normal & 3 & 3.3 \\
\hline 19 & Normal & Normal & Normal & Hypoplastic & 1 & 1.1 \\
\hline 20 & Normal & Normal & Normal & Absent & 3 & 3.3 \\
\hline 21 & Normal & Normal & Normal & Normal & 5 & 5.6 \\
\hline
\end{tabular}


$t$ tests using three items as the chance level of performance $(p<.001)$.

\section{Dichotic Listening Task}

\section{Age and sex effects}

For both groups, age and sex were not related to ear effects in any of the models and were removed from the final models.

\section{NC children}

A repeated-measures ANOVA with presentation ear as the repeated measure showed a significant REA for correctly reporting the $\mathrm{CV}$ syllables $[F(1,27)=7.37 ; p=.011$; partial eta $\left.{ }^{2}=.21\right]$, with participants correctly identifying a mean of $32.43(S E=2.083)$ right ear stimuli and a mean of $24.39(S E=1.43)$ left ear stimuli. These means were significantly above chance as determined by one sample $t$ tests $(p<.001)$ using six items as the chance level of performance.

\section{Children with SBM}

Ear by handedness. A mixed measures ANOVA with handedness as the between subjects factor and presentation ear as the repeated measure produced a significant handedness $\mathrm{X}$ ear interaction $[F(1,88)=4.75 ; p=.032$; partial eta $\left.^{2}=.05\right]$ (Figure 2a). Follow-up ANOVAS indicated that

Table 3. Relations between (a) status of the splenium and lesion level, (b) status of the splenium and handedness, and (c) lesion level and handedness, given in terms of frequency and \% in rows

\begin{tabular}{lrcc}
\hline \hline a. & \multicolumn{3}{c}{ Splenium } \\
\cline { 2 - 4 } & Absent & Hypoplastic & Present \\
\hline Handedness & & & \\
$\quad$ Right & $21(30.9 \%)$ & $37(54.4 \%)$ & $10(14.7 \%)$ \\
Left & $8(36.4 \%)$ & $12(54.5 \%)$ & $2(9.1 \%)$ \\
\hline
\end{tabular}

b.

\begin{tabular}{lrr} 
& \multicolumn{2}{c}{ Lesion level } \\
\cline { 2 - 3 } & \multicolumn{1}{c}{$\leq \mathrm{L} 1$} & $\geq \mathrm{T} 12$ \\
\hline Handedness & & \\
$\quad$ Right & $53(77.9 \%)$ & $15(22.1 \%)$ \\
Left & $18(81.8 \%)$ & $4(18.2 \%)$
\end{tabular}

c.

\begin{tabular}{lrrr} 
& \multicolumn{3}{c}{ Splenium } \\
\cline { 2 - 4 } & Absent & Hypoplastic & Present \\
\hline Lesion level & & & \\
$\leq \mathrm{L} 1$ & $19(26.8 \%)$ & $42(59.2 \%)$ & $10(14.1 \%)$ \\
$\geq \mathrm{T} 12$ & $10(52.6 \%)$ & $7(36.8 \%)$ & $2(10.5 \%)$ \\
\hline \hline
\end{tabular}
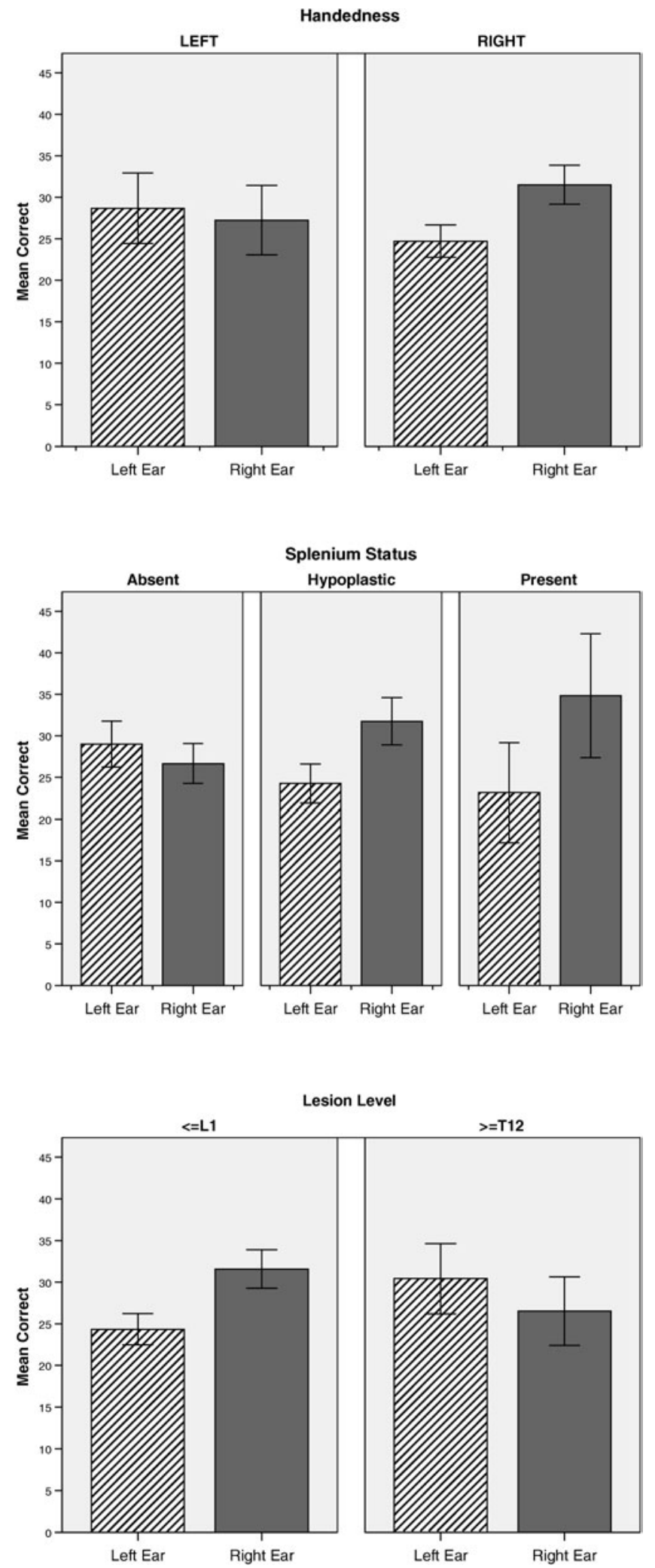

Fig. 2. a: Dichotic listening performance in children with spina bifida meningomyelocele: Handedness by presentation ear interaction. b: Dichotic listening performance in children with spina bifida meningomyelocele: Splenium status by presentation ear interaction. c: Dichotic listening performance in children with spina bifida meningomyelocele: Lesion level by presentation ear interaction. 
right-handers $(n=69 ; 75.6 \%)$ had a significant REA, $F(1,67)=12.96 ; p<.001 ;$ partial eta ${ }^{2}=.16$. Left-handers $(n=22 ; 24.4 \%)$ showed a nonsignificant LEA $(F<1.0)$. Right- and left-handers did not differ in correct identification of right ear syllables $[F(1,88)=3.68 ; p=.058$; partial eta $\left.^{2}=.04\right]$, nor did left-handers make more correct identifications of left ear syllables $[F(1,88)=3.28 ; p=.054$; partial eta $\left.{ }^{2}=.04\right]$. A similar analysis involving the handedness inventory data right- $(n=58 ; 64.4 \%)$, mixed- $(n=$ $15 ; 16.7 \%)$, and left-handers $(n=17 ; 18.9 \%)$ did not produce a significant ear by handedness interaction $[F(2,87)=$ 2.097; $p=.129$; partial eta $\left.{ }^{2}=.05\right]$.

Ear by status of the splenium analyses. Figure $2 \mathrm{~b}$ shows that the overall ANOVA involving presentation ear and status of the splenium resulted in a significant interaction, $F(2,87)=4.89 ; p=.01\left(\right.$ partial eta $\left.{ }^{2}=.10\right)$. Follow-up ANOVAS were conducted. Children with a normal splenium had a marked REA that did not achieve conventional levels of alpha, $F(1,11)=3.95 ; p=.072$, possibly due to the small sample size $(n=12)\left(\right.$ partial eta $\left.{ }^{2}=.26\right)$. Children with a hypoplastic splenium $(n=50)$ showed a significant REA, $F(1,49)=9.50 ; p=.003$; partial eta ${ }^{2}=.16$. Children missing a splenium $(n=31)$ had a small and nonsignificant LEA, $F<1$. A repeated measures ANOVA specifically conducted to examine the ear effect for children with SBM who were right handed and missing the splenium also produced a small nonsignificant LEA $(F<1)$.

Ear by status of the body analyses. Because only two children were missing the body of the $\mathrm{CC}$, no hypotheses about the absence of the body were tested. One of the children without a body showed an REA and the other had a LEA. An ANOVA involving presentation ear and status of the body (hypoplastic or normal) produced a significant REA, $F(1,86)=6.67 ; p=.012$; partial eta $\left.{ }^{2}=.07\right]$. The main effect of body status $(F=1.1)$ and the interaction of body status with ear were not significant $(F<1)$.

Ear by lesion level analyses. The mixed ANOVA involving presentation ear and lesion level produced a significant interaction, $F(1,88)=7.44 ; p=.008 ;$ partial eta ${ }^{2}=.08$ (Figure 2c). Follow-up ANOVAS indicated that children with lower $(\leq \mathrm{L} 1)$ lesions showed a significant REA, $F(1,70)=15.0 ; p<.001 ;$ partial eta ${ }^{2}=.18$. Children with upper ( $\geq \mathrm{T} 12)$ lesions had a small nonsignificant LEA $(F=$ 1.12). Right ear stimuli were correctly identified significantly more often by children with lower than upper lesions, $F(1,88)=4.156 ; p=.04$; partial eta ${ }^{2}=.05$. Left ear syllables were correctly identified significantly more often by children with upper than lower lesions, $F(1,88)=8.18 ; p=$ .005 ; partial eta ${ }^{2}=.09$. The number of correct syllable identifications did not differ in the two lesion level groups.

In general, the number of correct responses to right and left ear CV syllables made by children with SBM were significantly above chance as determined by one sample $t$ tests $(p=.001)$.

\section{DISCUSSION}

Our study provides important new information about the patterns of CC agenesis and hypoplasia in children with SBM and auditory IHT as a function of CC structural abnormalities, handedness, lesion level. In keeping with the first hypothesis, we found many patterns of regional CC agenesis and hypoplasia, the most common of which was hypoplasia of the entire $\mathrm{CC}$ in one fifth of the children, followed by agenesis of the rostrum and splenium combined with a hypoplasic genu and body in one tenth of the children. Complete $\mathrm{CC}$ agenesis was not observed but the $\mathrm{CC}$ was normal only in a small proportion of children with SBM (5.6\%; Table 2) as compared to the $100 \%$ in our NC children.

Auditory IHT was typical (an REA) in children in the NC group but atypical in the SBM group. As predicted, auditory IHT in children with SBM was influenced by the status of the splenium of the $\mathrm{CC}$, handedness, and lesion level. The patterns of IHT performance varied considerably with splenium status. Although we predicted that right-handed children with SBM and a missing splenium might show an exaggerated REA (Pollmann et al., 2002; Sugishita et al., 1995), the data did not support this prediction; indeed these children showed a nonsignificant LEA. Children with a normal splenium had a clear REA that did not differ from that of normal children. We did not find an exaggerated REA in our splenial agenesis or hypoplasia groups; in fact, there was a slight nonsignificant LEA when the splenium was absent and a strong REA when the splenium was hypoplastic. Although a relatively normal REA might be obtained with agenesis of the splenium if there were compensatory mechanisms operating for these children such as an intact or enlarged anterior commissure (Fischer et al., 1992), our MRI data (Hannay et al., in press) indicate that an enlarged anterior commissure is an unlikely compensatory mechanism for IHT in children with SBM. We could not examine fully the effects of status of the body because only 2 children had agenesis of the CC body. It is possible that agenesis of the splenium evident on the MRI in some of our children includes some degree of the posterior body. However, children with a normal or hypoplastic body showed a normal REA for CV syllables, either supporting the idea that the body is not so important in auditory IHT (Pollmann et al., 2002) or that a hypoplastic body is sufficient for auditory IHT

Relatively few MRI studies of children have noted hypoplasia as a structural abnormality (e.g., Kawamura et al., 2002), and then with relatively small samples (e.g., Tovar-Moll et al., 2007 identified hypoplasia in three patients with CC agenesis). We found that hypoplasia of the splenium was associated with a clear though somewhat smaller REA, suggesting that the fibers in a hypoplastic splenium are sufficient to transfer some auditory information, at least phonemes. It may be useful to administer a DL task involving semantic processing in the future since Huber-Okrainec et al. (2004) reported poor idiom comprehension in children with SBM having a hypoplastic CC and our stimuli just required basic perceptual dis- 
crimination. If auditory IHT is compromised for more complex auditory processing, then a reduced REA would be expected that would indicate that hypoplastic CC pathways are not as adequate as suggested by our current data.

The fact that ear effects on the DL task were related to handedness when bifurcated into right and left handedness suggests that handedness may be related to cerebral asymmetry for language in children with SBM. Of course, verification of this conclusion awaits the examination of children with SBM using functional neuroimaging modalities (Breier et al., 2006; Fernandes et al., 2006; Rimol et al., 2006). The sample was too small to permit an analysis of finer distinctions between handedness subgroups. A detailed examination of handedness in relation to structural abnormalities in our children with SBM is under way.

The relation between lesion level and status of the splenium is of special interest. Despite the lack of a significant relation between these two variables, an examination of Figures $2 \mathrm{~b}$ and $2 \mathrm{c}$, show that children with SBM with an absent splenium and those with a higher level spinal lesion ( $\geq$ T12) showed nonsignificant LEAs on the DL test. These means involve a reduction of correct identification of CVs presented to the right ear coupled with an increase in correct identification of CVs presented to the left ear, suggesting that the right hemisphere might be more involved in processing these stimuli. It is relevant to note that we found a significant relation between lesion level and status of the splenium in the larger group of children with SBM for whom we have MRIs (Fletcher et al., 2005) of which these children were a subsample. The fact that higher level spinal lesions were more common in the larger sample (9\%) than in the group that participated in this study may help to account for the lack of a significant relation between splenium status and lesion level.

To summarize, a typical REA in children with SBM was associated with a normal or hypoplastic CC splenium, right handedness, and lower level spinal lesions. While we do not have the sample size to examine the interaction of all of these factors in the same analysis, the children with REAs may be those with the best outcomes along a variety of dimensions and with brains that are less dysmorphic than those of other subgroups despite significant malformation and hydrocephalus (Fletcher et al., 2005). In contrast, left handedness, upper level lesions, and agenesis of the splenium were associated with lack of REA. Left handedness is associated with several neural anomalies and with less functional laterality of language in children with early brain injury (Satz et al., 1988). Children with SBM with upper level lesions have poorer neurobehavioral outcomes and more dysmorphic brains (Fletcher et al., 2005), so these findings are not surprising. Magnetoencephalography (MEG; Breier et al., 2006) is currently being used by our group to determine the hemisphere dominant for processing linguistic stimuli in a subset of children with SBM who have demonstrated a REA for CV syllables.

This research highlights the need for structural neuroimaging to verify the status of structures implicated in audi- tory IHT, to establish possible compensatory mechanisms in studies of the effects of complete or partial agenesis of the $\mathrm{CC}$ from congenital or acquired disorders, paralleling work in normal adults (Clarke et al., 1993). Further work needs to be done on the pattern of performance on various tasks as related to structural abnormalities and the shape and positioning of hydrocephalus in the brain of the SBM children. Advances in functional neuroimaging along with newer techniques for exploring the integrity of white matter pathways, such as diffusion tensor imaging (Hasan et al., 2008), might help determine the nature of the agenesis (i.e., which regions of the cortex are being connected by remaining fibers in the $\mathrm{CC}$ ) as well as functional and structural re-organization in the presence of $\mathrm{CC}$ anomalies.

\section{ACKNOWLEDGMENTS}

This research was funded by National Institutes of Child Health and Human Development Grant PO1 HD35946, "Spina Bifida: Cognitive and Neurobehavioral Variability." There are no relationships related with any commercial organizations related to this research or any other sources of financial support for this research. We acknowledge Joanne Robitaille, who was the first technician at the Hospital for Sick Children to work on this project and has since passed away. We also acknowledge the work of Andrea Martin with data collection, and Irene Townsend and Sue Inwood with recruitment.

\section{REFERENCES}

Alexander, M.P. \& Warren, R.L. (1988). Localization of callosal auditory pathways: A CT case study. Neurology, 38, 802-804.

Barkovich, A.J. (2005). Pediatric Neuroimaging (4th ed.). Philadelphia: Lippincott, Williams, \& Wilkins.

Beery, K. (1982). Revised Administration, Scoring, and Teaching Manual for the Development of Visual-Motor Integration. New York: Modern Curriculum Press.

Benavidez, D.A., Fletcher, J.M., Hannay, H.J., Bland, S.T., Caudle, S.E., Mendelsohn, D.B., Yeakley, J., Brunder, D.G., Harward, H., Song, J., Perachio, N.A., Bruce, D., Scheibel, R.S., Lilly, M.A., Verger-Maestre, K., \& Levin, H.S. (1999). Corpus callosum damage and interhemispheric transfer of information following closed head injury in children. Cortex, 35, 315-336.

Berlin, C.I., Lowe-Bell, S.S., \& Berlin, H.L. (1973). Dichotic right ear advantages in children 5 to 13. Cortex, 9, 393-401.

Bethmann, A., Tempelmann, C., De Bleser, R., Scheich, H., \& Brechmann, A. (2007). Determining language laterality by fMRI and dichotic listening. Brain Research, 1133, 145-157.

Breier, J.I., Maher, L.M., Novak, B., \& Papanicolaou, A.C. (2006). Magnetoencephalographic studies of language reorganization after cerebral insult. Archives of Physical Medicine and Rehabilitation, 87(Suppl. 2), S77-S83.

Bryden, M.P. (1982). Laterality: Functional Asymmetry in the Intact Brain. New York: Academic Press.

Bryden, M.P. (1988a). An overview of the dichotic listening procedure and its relation to cerebral organization. In K. Hugdahl (Ed.), Handbook of Dichotic Listening: Theory, Methods and Research (pp. 1-43). Chichester, UK: Wiley.

Bryden, M.P. (1988b). Cerebral specialization: Clinical and experimental assessment. In F. Boller \& J. Grafman (Eds.), Handbook of Neuropsychology (pp. 143-159). Amsterdam: Elsevier. 
Bryden, M.P. \& Allard, F. (1973). Dichotic listening and the development of linguistic processes. Paper presented at the International Neuropsychological Society. New Orleans, LA.

Bryden, M.P. \& Zurif, E.B. (1970). Dichotic listening performance in a case of agenesis of the corpus callosum. Neuropsychologia, 8, 371-377.

Caplan, B. \& Kinsbourne, M. (1981). Cerebral lateralization, preferred cognitive mode, and reading ability in normal children. Brain and Language, 14, 349-370.

Chiarello, C. (1980). A house divided? Cognitive functioning with callosal agenesis. Brain and Language, 11, 128-158.

Clarke, J.M., Lufkin, R.B., \& Zaidel, E. (1993). Corpus callosum morphometry and dichotic listening performance: Individual differences in functional interhemispheric inhibition? Neuropsychologia, 31, 547-557.

Cohen, J. (1973). Eta-squared and partial-eta squared in fixed factor ANOVA designs. Educational and Psychological Measurement, 33, 107-112.

Cohen, J., Cohen, P., West, S.G., \& Aiken, L.S. (2003). Applied Multiple Regression/Correlation Analysis for the Behavioral Sciences. (3rd ed.). New York: Lawrence Erlbaum Associates.

Cowell, P. \& Hugdahl, K. (2000). Individual differences in neurobehavioral measures of laterality and interhemispheric function as measured by dichotic listening. Developmental Neuropsychology, 18, 95-112.

Detrait, E.R., George, T.M., Etchevers, H.C., Gilbert, J.R., Vekemans, M., \& Speer, M.C. (2005). Human neural tube defects: Developmental biology, epidemiology, and genetics. Neurotoxicology and Teratology, 27, 515-524.

Fennell, E.B. (1986). Handedness in neuropsychological research. In H.J. Hannay (Ed.), Experimental Techniques in Human Neuropsychology. New York: Oxford.

Fernandes, M.A., Smith, M.L., Logan, W., Crawley, A., \& McAndrews, M.P. (2006). Comparing language lateralization determined by dichotic listening and $\mathrm{fMRI}$ activation in frontal lobes in children with epilepsy. Brain and Language, 96, 106-114.

Fischer, M., Ryan, S.B., \& Dobyns, W.B. (1992). Mechanisms of interhemispheric transfer and patterns of cognitive function in acallosal patients of normal intelligence. Archives of Neurology, 49, 271-277.

Fletcher, J.M., Copeland, K., Frederick, J., Blaser, S.E., Kramer, L.A., Northrup, H., Hannay, H.J., Brandt, M.E., Francis, D.J., Villarreal, G., Drake, J.M., Laurent, J.P., Townsend, I., Inwood, S., Boudousquie, A., \& Dennis, M. (2005). Spinal lesion level in spina bifida meningomyelocele: A source of neural and cognitive heterogeneity. Journal of Neurosurgery, 102, 268279.

Gadea, M., Gomez, C., \& Espert, R. (2000). Test-retest performance for the consonant-vowel dichotic listening test with and without attentional manipulations. Journal of Clinical and Experimental Neuropsychology, 22, 793-803.

Gazzaniga, M.S. (2000). Cerebral specialization and interhemispheric communication-Does the corpus callosum enable the human condition? Brain, 123, 1293-1326.

Geffner, D.S. \& Dorman, M.F. (1976). Hemispheric specialization for speech perception in four-year-old children from low and middle socio-economic classes. Cortex, 12, 71-73.

Halwes, T. (1991). User's manual for the fused words dichotic listening test. New Haven, CT: Precision Neurometrics.

Hannay, H.J. (2000). Functioning of the corpus callosum in children with early hydrocephalus. Journal of the International Neuropsychological Society, 6, 351-361.
Hannay, H.J., Dennis, M., \& Fletcher, J.M. (in press). Partial agenesis of the corpus callosum in spina bifida meningomyelocele and potential compensatory mechanisms. Journal of Clinical and Experimental Neuropsychology.

Harper, L.V. \& Kraft, R.H. (1994). Longitudinal change of ear advantage for receptive language function in $2 \frac{1}{2} 2$ - to 9 -year-old children. Perceptual and Motor Skills, 79, 1091-1102.

Hasan, K.M., Eluvathingal, T.J., Kramer, L.A., Ewing-Cobbs, L., Dennis, M., \& Fletcher, J.M. (2008). White matter microstructural abnormalities in children with spina bifida myelomeningocele and hydrocephalus: A diffusion tensor tractography study of the association pathways. Journal of Magnetic Resonance Imaging, 27, 700-709.

Hellige, J.B. (1983). Hemisphere $\times$ task interaction and the study of laterality. In J.B. Hellige (Ed.), Cerebral Hemisphere Asymmetry: Method, Theory, and Application. New York: Praeger.

Hiscock, M. \& Decter, M. (1988). Dichotic listening in children. In K. Hugdahl (Ed.), Handbook of Dichotic Listening: Theory, Methods and Research. New York: Wiley.

Hiscock, M., Inch, R., Jacek, C., Hiscock-Kalil, C., \& Kalil, K.M. (1994). Is there a sex difference in human laterality? I. An exhaustive survey of auditory laterality studies from six neuropsychology journals. Journal of Clinical and Experimental Psychology, 16, 423-435.

Hollingshead, A.A. (1975). A four-factor index of social status. Unpublished manuscript, Yale University, New Haven, CT.

Huber-Okrainec, J., Blaser, S.E., \& Dennis, M. (2004). Idiom comprehension deficits in relation to corpus callosum agenesis and hypoplasia in children with spina bifida meningomyelocele. Brain and Language, 93, 349-368.

Hugdahl, K., Carlsson, G., \& Eichele, T. (2001). Age effects in dichotic listening to consonant-vowel syllables: Interactions with attention. Developmental Neuropsychology, 20, 445-457.

Hugdahl, K., Helland, T., Faerevaag, M.K., \& Lyssand, E.T. (1995). Absence of ear advantage on the consonant-vowel dichotic listening test in adolescent and adult dyslexics: Specific auditoryphonetic dysfunction. Journal of Clinical and Experimental Neuropsychology, 17, 833-840.

Jun, C.L. \& Nutik, S.L. (1985). Surgical approaches to intraventricular meningiomas of the trigone. Neurosurgery, 16, 416-420.

Kawamura, T., Nishio, S., Morioka, T., \& Fukui, K. (2002). Callosal anomalies in patients with spinal dysraphism: Correlation of clinical and neuroimaging features with hemispheric abnormalities. Neurology Research, 24, 463-467.

Kimura, D. (1961a). Cerebral dominance and the perception of verbal stimuli. Canadian Journal of Psychology, 15, 166-171.

Kimura, D. (1961b). Some effects of temporal lobe-damage on auditory perception. Canadian Journal of Psychology, 15, 156-165.

Kimura, D. (1963). Speech lateralization in young children as determined by an auditory test. Journal of Comparative and Physiological Psychology, 56, 899-902.

Klaas, P.A., Hannay, H.J., Caroselli, J.S., \& Fletcher, J.M. (1999). Interhemispheric transfer of visual, auditory, tactile, and visuomotor information in children with hydrocephalus and partial agenesis of the corpus callosum. Journal of Clinical and Experimental Neuropsychology, 21, 837-850.

Knox, C. \& Kimura, D. (1970). Cerebral processing of nonverbal sounds in boys and girls. Neuropsychologia, 8, 227-237.

Lassonde, M., Bryden, M.P., \& Demers, P. (1990). The corpus callosum and cerebral speech lateralization. Brain and Language, 38, 195-206. 
Lassonde, M. \& Jeeves, M.A. (Eds.). (1994). Callosal Agenesis: A Natural Split Brain? New York: Plenum Press.

Levine, T.R. \& Hullett, C.R. (2000). Eta squared, partial eta, squared, and misreporting of effect size in communication research. Human Communication Research, 28, 612-625.

McGlone, J. (1980). Sex differences in cerebral asymmetry: A critical survey. Behavioral and Brain Sciences, 3, 215-227.

McKeever, W.F., Nolan, D.R., Diehl, J.A., \& Seitz, K.S. (1984). Handedness and language laterality: Discrimination of handedness groups on the dichotic consonant-vowel task. Cortex, 20, 509-523.

Musiek, F.E., Wilson, D.H., \& Pinheiro, M.L. (1979). Audiological manifestions in "split brain" patients. Journal of the American Audiological Society, 5, 25-29.

Neijenhuis, K., Snik, A., Priester, G., van Kordenoordt, S., \& van den Brock, P. (2002). Age effects and normative data on a Dutch test battery for auditory processing disorders. International Journal of Audiology, 41, 334-346.

Pierce, C.A., Block, R.A., \& Aquinis, H. (2004). Cautionary note on reporting eta-squared values from multi-factor ANOVA designs. Educational and Psychological Measurement, 64, 916-924.

Pollmann, S., Maertens, M., von Cramon, D.Y., Lepsien, J., \& Hugdahl, K. (2002). Dichotic listening in patients with splenial and nonsplenial callosal lesions. Neuropsychology, 16, 56-64.

Raczkowski, D., Kalat, J.W., \& Nebes, R. (1974). Reliability and validity of some handedness questionnaire items. Neuropsychologia, 12, 43-47.

Rimol, L.M., Specht, K., \& Hughahl, K. (2006). Controlling for individual differences in fMRI brain activation to tones, syllables and words. Neuroimage, 30, 554-562.

Satz, P., Bakker, D.J., Goebel, R., \& Van der Vlugt, H. (1975). Developmental parameters of the ear asymmetry: A multivariate approach. Brain and Language, 2, 171-185.

Satz, P., Nelson, L., \& Green, M. (1989). Ambiguous-handedness: Incidence in a non-clinical sample. Neuropsychologia, 27, 1309-1310.
Satz, P., Strauss, E., Wada, J., \& Orsini, D.L. (1988). Some correlates of intra- and interhemispheric speech organization after left focal brain injury. Neuropsychologia, 26, 345-350.

Springer, S.P. (1986). Dichotic listening. In H.J. Hannay (Ed.), Experimental Techniques in Human Neuropsychology (p. 161). New York: Oxford University Press.

SPSS, Inc. (2005). SPSS 14.0 for Windows. [Computer software]. Chicago: SPSS.

Sugishita, M., Otomo, K., Yamazaki, K., Shimizu, H., Yoshioka, M., \& Shinohara, A. (1995). Dichotic listening in patients with partial section of the corpus callosum. Brain, 118, 417-427.

Tabachnick, B.G. \& Fidell, L.S. (2005). Using Multivariate Statistics (5th ed.). Boston: Allyn and Bacon.

Thorndike, R.L., Hagen, E.P., \& Sattler, J.M. (1986). StanfordBinet Intelligence Scale (4th ed.). Chicago: Riverside.

Tovar-Moll, F., Moll, J., de Oliveira-Souza, R., Bramati, I., Andreiuolo, P.A., \& Lent, R. (2007). Neuroplasticity in human callosal dysgenesis: A diffusion tensor imaging study. Cerebral Cortex, 17, 531-541.

Van Eys, P.P. \& McKeever, W.F. (1988). Subject knowledge of the experimenter's interest in handedness and familial sinistrality variables and laterality test outcomes. Brain and Cognition, 7 , 324-334.

Volcik, K.A., Blanton, S.H., \& Northrup, H. (2001). Examinations of methylenetetrahydrofolate reductase C677T and A1298C mutations - and in utero viability. American Journal of Human Genetics, 69, 1150-1152.

Westerhausen, R., Kreuder, F., Dos Santos Sequeria, S., Walter, C., Woerner, W., Wittling, R.A., Schweiger, E., \& Wittling, W. (2006). The association of macro- and microstructure of the corpus callosum and language lateralization. Brain and Language, 97, 80-90.

Williams, L.J., Rasmussen, S.A., Flores, A., Kirby, R.S., \& Edmonds, L.D. (2005). Decline in the prevalence of spina bifida and anencephaly by race/ethnicity: 1995-2002. Pediatrics, 116, 580-586. 